\title{
Congenital cardiac anomalies with vein of Galen malformations in infants
}

\author{
D B McElhinney, V V Halbach, N H Silverman, C F Dowd, F L Hanley
}

\begin{abstract}
Published reports and personal experience are reviewed relating to patients under 1 year of age diagnosed with a vein of Galen malformation and congenital heart disease. Including five patients from this institution, a total of 23 patients (12 neonates) with congenital heart disease and a vein of Galen malformation have been reported. Six of these had sinus venosus atrial septal defect and nine had aortic coarctation.

(Arch Dis Child 1998;78:548-551)
\end{abstract}

Keywords: vein of Galen malformation; congenital heart disease, atrial septal defect; coarctation of the aorta

Vein of Galen malformations are the most common form of symptomatic cerebrovascular malformation in neonates and infants. ${ }^{1}$ Typically, newborns and young infants with a symptomatic vein of Galen malformation present with intractable heart failure, which is the most common cause of death in such patients. ${ }^{12}$ Although there have been isolated case reports of congenital heart disease associated with arteriovenous malformations of the cerebral circulation (table 1), there have been no comprehensive reviews of this topic. After treating a patient who had an unusual and potentially serious complication resulting from the coexistence of these conditions, we reviewed published reports and our own experience to assess the incidence and distribution of congenital heart disease in neonates and infants with vein of Galen malformations.

Cardiothoracic

Surgery, University of

California San

Francisco, San

Francisco, California, USA

D B McElhinney

F L Hanley

Division of Pediatric Cardiology, University of California San

Francisco

N H Silverman

Division of

Neuroradiology,

University of

California San

Francisco

V V Halbach

C F Dowd

Correspondence to: Dr D B McElhinney, 505 Parnassus Avenue, M593 San Francisco, CA

94143-0118, USA.

Accepted 4 December 1997

\section{Patients and abnormalities}

Between 1983 and 1996, 25 neonates and infants with congenital vein of Galen malformations underwent echocardiography at our institution before surgical or endovascular treatment, some of whom were included in previous reports. ${ }^{1516}$ At the time of echocardiography, patients ranged in age from two fetuses at 36 weeks' gestation to an 11 month old infant (median age 7 days; 19 neonates). Complete echocardiographic evaluation and head ultrasound were performed according to previously described methods. ${ }^{15}$ Patent arterial duct and patent foramen ovale were not included as congenital heart disease.

Congenital cardiovascular anomalies were identified by echocardiography in five of our 25 patients. One patient had a sinus venosus atrial septal defect with partially anomalous pulmonary venous return to the superior cavoatrial junction and two muscular ventricular septal defects; one had complete atrioventricular sep- tal defect; one had secundum atrial septal defect; one had perimembranous ventricular septal defect with secundum atrial septal defect; and one had coarctation of the aorta. Apart from structural anomalies, mild to severe dilatation of the superior caval vein and its immediate tributaries, as well as the right sided cardiac chambers and pulmonary arteries, was observed in 21 patients.

One patient experienced an unusual complication related to the coexistence of congenital heart disease and a vein of Galen malformation. This patient was referred to our institution at 26 days old for treatment of a vein of Galen malformation fed by multiple branches of the left posterior choroidal and right pericallosal arteries (fig 1A and B). Echocardiography showed a sinus venosus atrial septal defect with anomalous drainage of the right pulmonary veins to the superior cavoatrial junction, and two small muscular ventricular septal defects. During the first stage of treatment, which consisted of transarterial embolisation of the feeding arteries, a small perforation was made in the aneurysm, which was treated by coil embolisation. During the venous phase of the procedure three days later, a single errant coil was dislodged from the malformation and embolised distally. Chest radiography and echocardiography after the procedure showed the coil to be lodged in the trabeculae of the left ventricle, directly beneath the posterior leaflet of the mitral valve (fig 2). Over the next five months, the patient underwent repair of the cardiac defects and transcatheter closure of a residual fistula into the vein of Galen malformation (fig $1 \mathrm{C}$ and D). At two years' follow up the coil in the left ventricle had not shifted in location and there was no mitral valve dysfunction.

\section{Discussion}

To our knowledge congenital cardiac defects associated with vein of Galen malformations have been reported in 18 patients ranging in age from 1 day to 16 months (11 neonates). Noteworthy is the concentration of cases with aortic coarctation and sinus venosus atrial septal defect (table 1). Diagnosis of cardiac disease in these 18 patients was at necropsy in 12 , by echocardiography in five (four postnatal, one fetal), and by angiography in one. nologies and endovascular treatment, vein of Galen malformations were fatal in $90 \%$ of patients under 1 month of age and half of those between 1 month and 1 year. ${ }^{1}$ Treatment of this lesion has been revolutionised by transcatheter embolisation techniques, with $70-80 \%$ survival
Before the era of sophisticated imaging tech- 
Table 1 Reported cases of congenital heart disease associated with vein of Galen malformations

\begin{tabular}{|c|c|c|}
\hline Congenital cardiovascular anomaly & $n$ & Reference \\
\hline Sinus venosus atrial septal defect & 6 & $\begin{array}{l}\text { Friedman }{ }^{3} \text { Hernandez } \\
\text { Gomez } \\
5 \text { Present report }\end{array}$ \\
\hline Coarctation of the aorta/isthmic hypoplasia & 9 & $\begin{array}{l}\text { Gomez }^{5} \text { Comstock }^{6} \text { Reif }^{7} \\
\text { Jellinger } \\
\text { Present } \text { Clement }^{9} \text { Carroll }^{10}\end{array}$ \\
\hline $\begin{array}{l}\text { Partially anomalous pulmonary venous drainage (of the right upper and middle } \\
\text { pulmonary veins) to the superior vena cava }\end{array}$ & $1^{\star}$ & Levine $^{11}$ \\
\hline Ventricular septal defect & 3 & Clement $^{9}$ Present report \\
\hline Transposition of the great arteries & 1 & Hirano $^{12}$ \\
\hline Tetralogy of Fallot & 1 & Rubinstein $^{13}$ \\
\hline Atrioventricular septal defect & 1 & Present report \\
\hline Secundum atrial septal defect & 2 & Present report \\
\hline Unspecified $\dagger$ & 1 & Lasjaunias $^{14}$ \\
\hline
\end{tabular}

Because two patients in our series had both a ventricular septal defect and a secundum or sinus venosus atrial septal defect, individual lesions listed do not total 23, which is the total number of patients in whom defects were present.

*This lesion is almost always found with a sinus venosus atrial septal defect, though the authors reported that there was no interatrial communication in this case.

tA neonate with a vein of Galen malformation and surgical congenital heart disease was noted to have undergone cardiac surgery and died, but the type of heart defect was not specified.

among neonates and young infants, and cure rates of approximately $50 \% .^{16}{ }^{17}$ However, endovascular treatment has not been without complications, including perforation of the thin walled aneurysm or the feeding vessels (as occurred during the arterial embolisation stage in our patient), cerebral infarction, and other neurological sequelae. ${ }^{16}{ }^{17}$ Another complication, sometimes fatal, has been distant migration of emboli delivered into the aneurysm by the transvenous route. ${ }^{17}$ Our patient is an unusual example of such an event, where a sinus venosus atrial septal defect allowed for paradoxical embolisation of a dislodged coil to the left ventricle. Embolisation to the distal cerebral vasculature has been reported in patients undergoing treatment for vein of Galen malformations, but in most such cases there was migration of non-absorbable liquid polymers used in particulate embolisation techniques. ${ }^{17}$

\section{PATHOGENESIS}

It is interesting that six of the 23 reported cases of congenital heart disease with vein of Galen malformations have been sinus venosus atrial septal defects, which are typically associated with anomalous drainage of the right pulmonary veins into the superior caval vein or right atrium. In addition, one other case had anomalous drainage of the right upper and middle pulmonary veins to the superior vena cava, which nearly always occurs with a sinus venosus atrial septal defect, although an atrial defect was not reported in this case. ${ }^{18}$ Atrial septal defects constitute an estimated $7 \%$ of congenital heart defects, and sinus venosus
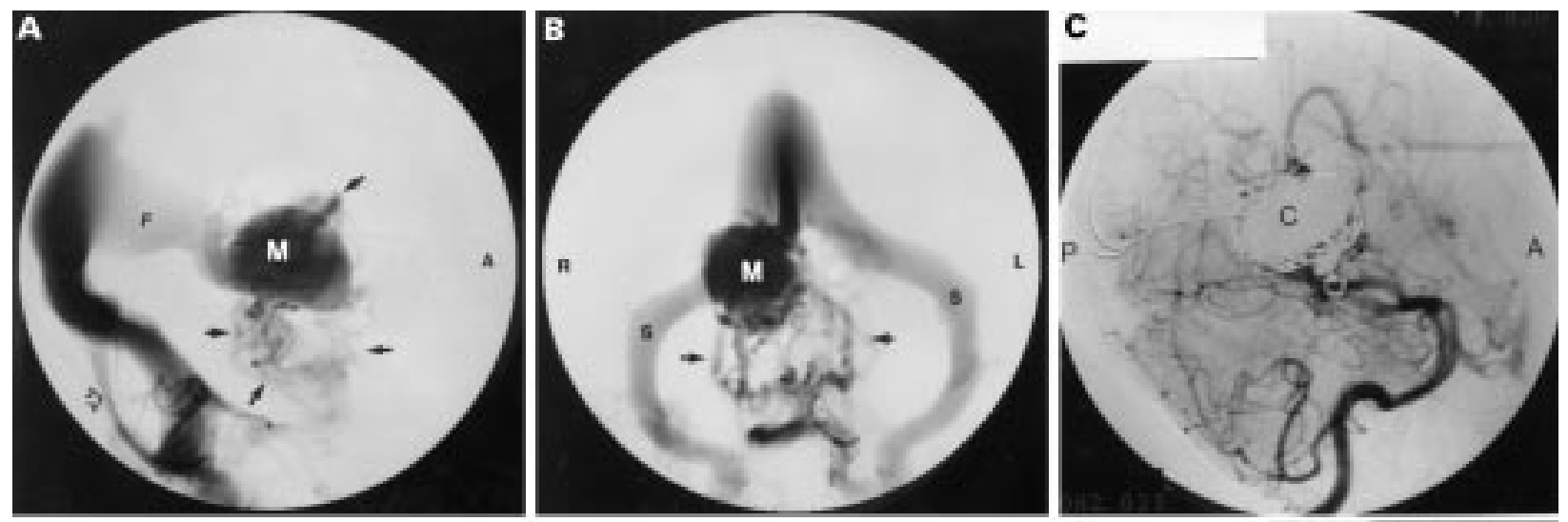

Figure 1 Digital subtraction cerebral angiograms taken immediately before the first coil embolisation ( $A$ and $B)$ and following completion of the third embolisation procedure (C and $D)$. Biplane left vertebral artery angiogram in lateral $(A)$ and frontal $(B)$ projections, showing multiple arteries (solid arrows) feeding into the aneurysmal vein of Galen malformation (M), which drains through abnormal falcine ( $F$ ) and occipital sinuses (open arrow), and then through anatomically normal appearing but dilated transverse and sigmoid sinuses (S). There is no appreciable arterial flow to the normal distribution of the posterior cerebral circulation. Similar biplane left vertebral arteriogram in lateral $(C)$ and frontal $(D)$ projections, showing normal flow to the posterior cerebrum as well as complete obliteration of the vein of Galen malformation with no residual flow. Multiple coils $(C)$ can be seen occupying the space of the malformation in $(C)$ and $(D)$. A, anterior; $P$, posterior; L, left, $R$, right.

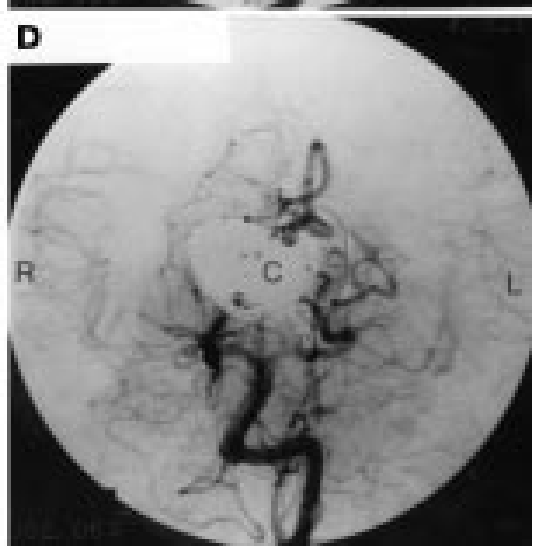



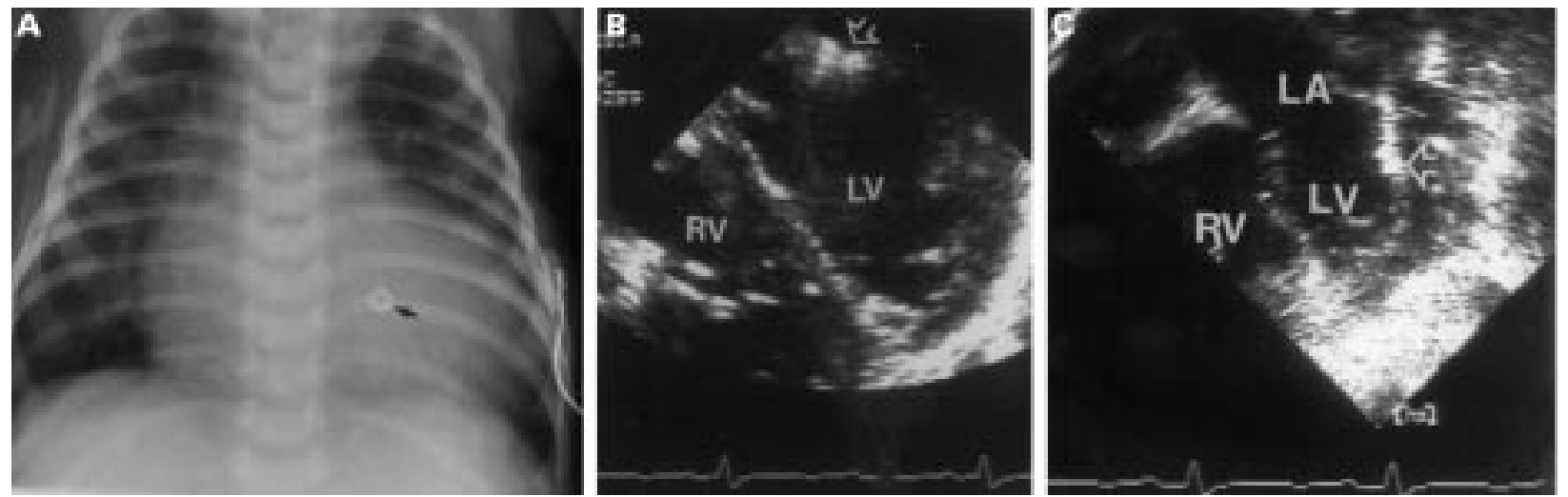

Figure 2 (A) Anteroposterior chest radiograph taken four days after the second embolisation procedure showing the radio-opaque coil in the area of the left ventricle (arrow). (B) Intraoperative transoesophageal echocardiography (intermediate between the ventricular long and short axis) performed before correction of the atrial septal defect, showing the echogenic coil (open arrow) along the posterior wall of the left ventricle (LV), located just beneath the mitral valve (RV, right ventricle). (C) Transgastric four-chamber view obtained during the same intraoperative transoesophageal echocardiography. The coil (open arrow) is visible along the posterior lateral wall of the LV (LA, left atrium).

defects comprise only $5-10 \%$ of atrial septal defects, or fewer than $1 \%$ of congenital heart defects. ${ }^{18}$

This overrepresentation of sinus venosus atrial septal defects in patients with vein of Galen malformations suggests that the association may be related to factors other than chance alone. In a report describing three patients with a vein of Galen malformation and sinus venosus atrial septal defect, Friedman et al hypothesised that increased superior caval return in utero may interfere with absorption of the right horn of the sinus venosus into the right atrium, ${ }^{3}$ which is thought to be the developmental defect involved in the formation of sinus venosus atrial septal defect with anomalous pulmonary venous drainage. From what is known about the timing of organogenesis, this hypothesis is plausible, assuming that absorption of the sinus venosus into the right atrium is completed around the eighth week of gestation, while the events responsible for formation of the vein of Galen malformation probably take place between 6 and 11 weeks' gestation. ${ }^{2}$ Despite uncertainty regarding the nature of the association between sinus venosus atrial septal defects and vein of Galen malformations, this association may be important clinically. Unlike other types of atrial septal defect, sinus venosus defects are accompanied by a superior caval vein that overrides the septal defect, promoting direct drainage of superior caval return to the left atrium and thus facilitating paradoxical embolisation.

Another notable association was that between coarctation of the aorta and vein of Galen malformations. Nine of the 23 patients with vein of Galen malformations and congenital cardiovascular disease had either a discrete coarctation or hypoplasia of the aortic isthmus. One of the two main theories proposed to explain the development of aortic coarctation holds that increased right ventricular output in utero leads to increased flow across the arterial duct and reduced antegrade flow across the aortic isthmus. ${ }^{19}$ This is consistent with coarctation in the setting of a vein of Galen malformation, in which case low resistance in the malformation will lead to decreased antegrade flow from the ascending aorta to the isthmus.
Also, cases of coarctation in patients with vein of Galen malformations-in which the coarctation has usually been described as mild-may simply reflect relative coarctation, insofar as the isthmus is the narrowest segment of the aortic arch, while the ascending aorta and transverse arch can be tremendously dilated in patients with high output distributed largely to the brain.

EVALUATION AND MANAGEMENT

A vein of Galen malformation is likely to be the dominant lesion in neonates who also have congenital heart disease. In such cases, repair or palliation of the vein of Galen malformation will almost always take priority over correction of the cardiac defects, except possibly in cardiac surgical emergencies such as obstructed total anomalous pulmonary venous return. Management of the vein of Galen malformation should not be altered because of a congenital heart defect. More thorough reports on this topic are available for detailed discussion of management. ${ }^{216}$ We emphasise that survival of neonates and infants with vein of Galen malformations has improved dramatically with the evolution of endovascular treatment.

Coexisting heart defects can still be critically important in the management and outcome of these patients, in part because of the potential for serious complications such as paradoxical embolisation. Thus, full echocardiographic evaluation with attention to the aortic arch and pulmonary veins is imperative. It is important to recognise the potential importance of a sinus venosus atrial septal defect (or any other shunt lesion) in the setting of a cerebral arteriovenous malformation, which leads to a high volume of systemic venous return and a large right to left shunt. Aortic coarctation varies in severity, and most cases reported with a vein of Galen malformation have been mild. Regardless of the severity of the narrowing, however, coarctation increases vascular resistance to the lower extremities and thus promotes flow through the low resistance circuit of the vein of Galen malformation. A severely symptomatic infant with such a malformation may be one of the select instances in which percutaneous dilatation of 
coarctation is advisable, mainly because the dilatation can be performed during the same catheterisation procedure as embolisation of the cerebral malformation. It should be recognised, however, that neonatal dilatation of coarctation has a high rate of recurrence.

1 Johnson IH, Whittle IR, Besser M, Morgan MK. Vein of Galen malformation: diagnosis and management. Neurosurgery 1987;20:747-58.

M, Hald JK. Aneurysms of the vein of Galen: embryonic considerations and anatomical features relating to the pathogenesis of the malformation. Neuroradiology 1989;31:109-28.

3 Friedman DM, Rutkowski M, Madrid M, Berenstein A. Sinus venosus atrial septal defect associated with vein of Galen malformations: report of two cases. Pediatr Cardiol 1994;15:50-2.

4 Hernandez A, Schwartz HG, Goldring D. Cerebral arteriovenous fistulas and congenital heart disease. $\mathcal{f}$ Pediatrics 1965;66:722-8.

5 Gomez MR, Whitten CF, Nolke A, Bernstein J, Meter JS Aneurysmal malformation of the great vein of Galen causing heart failure in early infancy: report of five cases. Pediatrics 1963:31:400-11.

6 Comstock CH, Kirk JS. Arteriovenous malformations: locations and evolution in the fetal brain. $\mathcal{F}$ Ultrasound $\mathrm{Med}$ 1991;10:361-5.

7 Reif RM. Arteriovenous aneurysm of the vein of Galen combined with coarctation of the aorta in a newborn. Isr $\mathcal{F}$ Med Sci 1980;16:785-6.

8 Jellinger K, Kucsko L, Seitelberger F. Diffuse meningocerebrale angiodysplasie mit hypoplasiogener isthmusstenosis bei einem neugeborenen. Beitr Path Anat 1966;133: 41-72.
9 Clement R, Gerbeaux J, Combes-Hamelle A, Pertuiset B, Pétranca C. Anéurysmes artérioveineux de l'ampoule de Galien chez le nourrisson. Presse Méd 1954;62:658-61.

10 Carroll CPH, Jakoby RK. Neonatal congestive heart failure as the presenting symptom of cerebral arteriovenous malformation. I Neurosurg 1966;25:159-63.

11 Levine OR, Jameson AG, Nellhaus G. Gold AP. Cardiac complications of cerebral arteriovenous fistula in infancy. Pediatrics 1962;30:563-75.

12 HiranoA, Solomon S. Arteriovenous aneurysm of the vein of Galen. Arch Neurol 1960;5:589-93.

13 Rubinstein LJ, Russell DS. Pathology of tumors of the nervous system. Baltimore, Williams \& Wilkins, 1971.

14 Lasjaunias P, Rodesch G, Terbrugge K, et al. Vein of Galen aneurysmal malformations: report of 36 cases managed between 1982 and 1988. Acta Neurochir (Wien) 1989;99: 26-37.

15 Ciricillo SF, Schmidt KG, Silverman NH, et al. Serial ultrasonographic evaluation of neonatal vein of Galen malformations to assess the efficacy of interventional neuroradiological procedures. Neurosurgery 1990;27:544-8.

16 Dowd CF, Halbach VV, Higashida RT, Fraser KW, Smith TP, Hieshima GB. Endovascular management of vein of Galen malformations. New trends in management of cerebrovascular malformations. New York: Springer-Verlag, 1994. 553-8.

17 Wisoff JH, Berenstein A. Interventional neuroradiology. In: Edwards MSB, Hoffman HJ, eds. Cerebral vascular disease in children and adolescents. Baltimore: Williams and Wilkins, 1989:139-57.

18 Porter CJ, Feldt RH, Edwards WD, Seward JB, Schaff HV. Atrial septal defects. In: Emmanouilides GC, Riemenschneider TA, Allen HD, Gutgesell HP, eds. Moss and Adams heart disease in infants, children and adolescents, 5th ed. Baltimore: Williams and Wilkins, 1995:687-703.

19 Rudolph AM, Heymann MA, Spitznas U. Hemodynamic considerations in the development of narrowing of the aorta. Am f Cardiol 1972;30:514-25. 